\title{
Post Materialism and Comparative Economic Development: Do Institutions Act as Transmission Channel?
}

\author{
Jacob A. Jordaan ${ }^{1}$ (D) Bogdan Dima ${ }^{2}$
}

Accepted: 1 October 2019 / Published online: 15 October 2019

(c) The Author(s) 2019

\begin{abstract}
Although a growing number of countries are experiencing structural societal changes characterised by an increased prominence of post materialistic societal goals and personal values, there is limited empirical evidence on the economic effects of post materialism. In this paper, we address this gap in the literature by estimating the effect of post materialism on the level of economic development for a heterogeneous set of countries. Furthermore, in line with the notion that institutions may act as transmission channel of economic effects of social values, we estimate whether institutions transmit indirect effects from post materialism. Our findings show that post materialism and institutions both generate sizeable effects on economic development. Institutions create consistent positive effects. The effect of post materialism consists of a negative direct effect and a larger positive indirect effect transmitted via institutions related to personal freedom, a solid regulatory framework and low corruption. These findings reflect the importance of accounting for the effects of social values such as post materialism and institutions as well as their interrelationship to identify more fully their impact on economic development.
\end{abstract}

Keywords Post materialism · Institutions · Economic development · Transmission channels $\cdot$ World values survey $\cdot$ European values study

Electronic supplementary material The online version of this article (https://doi.org/10.1007/s1120 5-019-02205-w) contains supplementary material, which is available to authorized users.

Jacob A. Jordaan

j.a.jordaan@uu.nl

Bogdan Dima

bogdan.dima@e-uvt.ro

1 Utrecht University School of Economics, Adam Smith Hall, International Campus Utrecht, Kriekenpitplein 21-22, 3584 EC Utrecht, The Netherlands

2 Faculty of Economics and Business Administration, West University of Timisoara, Str. J.H. Pestalozzi 16, 300115 Timisoara, Romania 


\section{Introduction}

The last decades have seen important changes in research on causes of international income differences. Following extensive research on the growth effects of physical and human capital accumulation and technological change, recent studies are increasingly characterised by estimating effects of fundamental causes of long run growth (Spolaore and Wacziarg 2013). One research strand focuses on the central importance of institutions for economic behaviour and outcomes (North 1990; Acemoglu et al. 2005; Jones and Romer 2010; Lloyd and Lee 2016). An often-cited contribution to this research field is Rodrik et al. (2004), who present econometric evidence indicating that institutional quality, measured by rule of law, is strongly related to cross-country income differences, rendering alternative explanations related to differences in trade policy and geographical factors largely insignificant. Other examples of studies that provide evidence of economic effects of a variety of institutional country characteristics include Hall and Jones (1999), Acemoglu and Johnson (2005) and Gorodnichenko and Roland (2011).

Another strand of the literature on fundamental causes of economic growth and development is investigating the effects of culture and social values (Guiso et al. 2006; Alesina and Giuliano 2015; Bjørnskov 2017). A well-known study is Tabellini (2010), who finds that cultural traits related to respect for others and confidence in self-determination are significantly associated with the existence of persistent income differences between regional economies in the European Union (EU). Several other studies provide corroborating evidence that countries or regions with a high level of interpersonal trust are characterised by higher growth rates (e.g. Beugelsdijk and van Schaik 2005; Horvath 2013). Related studies report similar positive effects of the degree of associational activity or social capital on economic development (Akçomak and ter Weel 2009; Westlund and Adam 2010).

Our paper is related to these two research strands in two ways. First, by investigating the effect of post materialism on comparative economic development, we examine a type of social value that has been largely overlooked in research that treats social values as a fundamental cause of international income differences. This omission is important, given findings from sociological and political science research on processes of socio-economic transformations that show that post-materialistic norms and values have become more prominent during the last decades (Inglehart 1988; Inglehart and Welzel 2005). As more and more citizens in a growing number of countries have reached a state of affluence where their basic needs related to survival and security are met, social and individual priorities are changing with greater importance being assigned to non-materialistic goals and values such as quality of life, social equality, autonomy and personal freedom (Inglehart and Welzel 2005).

Importantly, it is difficult to predict a priori the economic effect of the growing prominence of post materialism. On the one hand, the change in values and priorities can be expected to create a dampening effect on economic growth (Abramson and Inglehart 1995). The pursuit of non-materialistic goals reflects a decreasing valuation of profit and income maximisation and may also lead to additional economic costs, which in combination are likely to have a negative impact on economic development. On the other hand, the growing importance of post materialistic values related to independence and autonomy may generate positive economic effects. Although post materialism is closely linked to the pursuit of non-materialistic goals that are beneficial at the societal level, it also involves, at the individual level, a growing appreciation of self-expression, autonomy and economic freedom (Welzel 2010; Wilson 2005). Given evidence of positive associations between 
individualism and economic development (Gorodnichenko and Roland 2011, 2017), it may similarly be the case that the post materialistic valuation of personal autonomy and economic freedom generates positive economic effects. Given the scarcity of concrete evidence of the effects of post materialism, our paper therefore provides important new empirical evidence both on the nature and the scale of the economic effect of post materialism.

Second, our paper contributes to the literature on the economic effects of institutions and the interrelationships between social values, institutions and economic development. In line with the framework of distinct and hierarchical levels of institutions (North 1990) and the hierarchy of social analysis (Williamson 2000), several studies find that cultural traits and social values influence the level and the quality of institutions (Alesina and Giuliano 2015). For instance, Aghion et al. (2010) report strong negative associations between various measures of interpersonal trust or trust in institutions and degrees of government regulation. Similarly, Davis and Williamson (2016) find that countries with a relative high degree of individualism are characterised by lighter regulations regarding firm entry. Another example is Guiso et al. (2004, 2008), who examine factors that influence financial development and find that both social capital and trust are positively associated with several aspects of financial institutions related to stock market participation and the use of bank loans.

In the present paper, we merge the literatures on social values and institutions by interpreting the evidence that social values influence institutions as an important indication that institutions may act as a transmission channel of an indirect economic effect of social values (see e.g. Boulila et al. 2008; Bjørnskov and Méon 2015). If institutions and social values affect economic development and social values influence institutions, institutions may transmit (part of) the economic effect of social values. Although intuitively appealing, only a few studies have examined this role of institutions as transmission channel (e.g. Bjørnskov 2012; Jordaan et al. 2016). We believe that it is likely that such indirect economic effects materialise from post materialism via institutions. The reason for this is that post materialistic citizens are prone to be politically active in terms of voicing their opinions and exerting pressure on the political establishment (e.g. Opp 1990; Welzel et al. 2003; Copeland 2014). This means that they can be assumed to challenge existing institutions in order to advance their values and priorities. If they are successful in doing so, they may create indirect effects on economic development via their impact on institutions. Therefore, we account in our analysis for the economic effects of both post materialism and a variety of institutions and the possible interrelationship that may exist between post materialism and these institutions. This ensures that we are able to distinguish between the direct effects of post materialism and institutions on economic development and the indirect effect of post materialism that is transmitted via institutions.

The paper is constructed as follows. Section 2 presents a literature review which we use to inform our research questions. Section 3 discusses the data, model and identification strategy. Section 4 presents the main empirical findings, which can be summarised as follows. First, the estimation of models on causes of international income differences that control for post materialism whilst omitting controls for institutions produces significant positive effects of post materialism. These estimated positive effects are robust to the use of different time frames and sample compositions, different indicators of post materialism and the use of several different instruments that control for endogeneity of the post materialism variables. Second, findings from three stages least squares (3SLS) estimations show that the estimated direct economic effects of institutional country characteristics related to personal freedom, a solid regulatory framework and low corruption are consistently positive. Furthermore, the inclusion of the institutional variables causes the estimated direct effect 
of post materialism to turn negative. Third, within the 3SLS framework that we specify, the findings also indicate that institutions act as a transmission channel of an indirect effect of post materialism on economic development. A further analysis of the findings reveals that the indirect effect from post materialism that runs via institutions is larger than its negative direct effect, resulting in an aggregate positive effect of post materialism on the level of economic development. Finally, Sect. 5 summarises and concludes.

\section{Literature Review and Research Questions}

\subsection{Post Materialism}

Findings from the rapidly developing literature on fundamental causes of international income differences indicate strongly that social values can exercise important effects on economic behaviour and outcomes. A range of cultural traits and social values is examined, following original research on the economic effects of factors including interpersonal trust (Zak and Knack 2001), social capability (Temple and Johnson 1998) and social capital (Knack and Keefer 1997). Guiso et al. (2006), Alesina and Giuliano (2015) and Spolaore and Wacziarg (2013) provide comprehensive surveys of the large body of evidence that has developed in the last decades. Overall, these surveys find that, within a large variety of empirical frameworks, the majority of evidence indicates that social values are significantly affecting economic performance, fostering the growing recognition of social values as fundamental driver of economic development (Alesina and Giuliano 2015).

Given the variety of social values that is analysed, it is striking that the concept of post materialism has remained largely unexamined in this research strand. Initiated by the seminal work by Inglehart (1971, 1977), research in the fields of sociology and political science has identified wide-ranging processes of structural socio-economic change, characterised by the growing adoption of new values and priorities. In particular, growing numbers of citizens in a variety of countries are substituting values such as quality of life and social equality for materialistic values that are primarily geared towards the maximisation of production and income. Furthermore, post materialistic citizens are characterised by a strong valuation of autonomy, economic independence and self-expression (Inglehart and Welzel 2005; Inglehart 2008; Delhey 2010).

The increasing prominence of post-materialism can be explained by two mechanisms, labelled the scarcity and the socialisation hypotheses (Inglehart 1971, 1977). The scarcity hypothesis is based on the recognition that people value and prioritise their most pressing needs. When their level of income is sufficiently high to not have to worry about survival and physical security, non-materialistic priorities such as quality of life, personal freedom and social equality become more important. Rising levels of income have resulted in more and more citizens in a growing number of countries living in a state of affluence where the substitution of such non-materialistic values for materialistic priorities has become possible (Inglehart and Welzel 2005; Inglehart 1997), fostering the development of post materialism.

The socialisation hypothesis explains why the rise of post materialism materialises as a long term and structural process. To a large extent, the values and beliefs that a person holds in her or his adult life reflect the conditions that prevailed during the person's preadult years (Inglehart 1997). This means that citizens that hold post materialistic values in their adult lives grew up under economic conditions that allowed for such values to become 
important. As such, the growing importance of post materialism can be seen as a process of intergenerational change. Ongoing processes of economic development have resulted in successive generations containing larger shares of citizens that grew up with a sense of existential security, allowing for the growing prominence of post materialistic values (Inglehart and Welzel 2005; Abramson and Inglehart 1995). ${ }^{1}$

Accepting the notion that social values generate economic effects suggests strongly that the growing importance of post-materialistic values and priorities is likely to generate important effects on economic behaviour and outcomes. It is difficult to predict the nature of these effects a priori, however. The commonly held assumption in sociological and political science research is that the growing importance of post materialism creates a dampening effect on economic growth, due to the decreasing prominence of income and profit maximisation (Abramson and Inglehart 1995). The scant direct evidence of such negative effects is conflicting, however. Granato et al. (1996) present evidence from ordinary least squares (OLS) estimations for a small cross-section of countries that suggests that the degree of post materialism in a country is negatively associated with economic growth. However, Edwards and Patterson (2009) re-examine the study by Granato et al. (1996) by broadening the set of countries and using a wider range of estimators and find no evidence that post materialism is significantly associated with economic growth.

Some other studies present evidence of a more indirect nature that suggests that post materialism may create negative economic effects. Delhey (2010) uses data from the World Values Survey for 52 countries and finds that in countries with a relative high level of post materialism, people place a relative high value on personal autonomy-relative to income-as source of self-reported well-being. This reflects the decreasing importance of production and income maximisation under post materialism. Another type of evidence is presented by Welzel et al. (2003), who find that post materialistic citizens value social equality. The advancement of social equality is expensive for governments to pursue and entails foregoing expenditures and investments in other areas, which may have a dampening effect on economic growth. In similar fashion, findings presented by Fairbrother (2013) that citizens with post materialistic values are more inclined to pay for the protection of the environment can also be interpreted as evidence that post materialism introduces additional costs into economic systems, lowering economic growth.

In contrast, there is also evidence that suggests that elements of post materialism may generate positive economic effects. Jordaan et al. (2016) argue that post materialistic citizens are more likely to operate on stock markets, as they value economic autonomy and want to make independent financial investments. This is corroborated by their findings that identify a robust positive effect of post materialism on the size of stock markets. In turn, as stock market development fosters economic growth (see Levine 2005), a rise in post

\footnotetext{
1 As Delhey (2010) rightly points out, the theory on post materialism has been subject to changes over the years. In particular, following the initial work on post materialism, Inglehart (1997) and Inglehart and Welzel (2005) have placed the concept of post materialism in a broader process of growing post modernisation. Given that we use indicators of post materialism for the mid-1990s as our key explanatory variable, we use the term post materialism in this paper, referring to values that are distinctly different from materialistic values of income and production maximisation, both from a societal and from an individual point of view. Also, the concept of post materialism is not undisputed and has been criticised on theoretical, methodological and empirical grounds. Abramson (2011) provides a comprehensive and detailed description of the development of the concept of post materialism and its critiques and counter-critiques over the last decades. This debate lies outside the scope of the present paper, given our primary goal of obtaining new empirical evidence on the economic effects of post materialism.
} 
materialism can create a positive indirect economic effect. Findings from the large number of studies that identify positive economic effects from economic freedom (see De Haan et al. 2006; Doucouliagos and Ulubasoglu 2006) can also be interpreted as indirect evidence that post materialism may create positive economic effects. Given that post materialists value economic freedom, the growing prominence of post materialism may indirectly foster economic development. This may also be the case for post materialistic values of individualism and autonomy. Gorodnichenko and Roland (2011, 2017) conduct extensive sets of estimations and find that various dimensions of individualism are positively associated with long run growth. As post materialists value autonomy and independence, it may also be the case that these traits impact positively upon long run growth.

\subsection{Institutions and Post Materialism}

Irrespective of the type of social value that we want to examine, the effect of institutions on economic development needs to be accounted for. Over the last decades, a wealth of evidence has become available indicating that institutions provide an important explanation for international income differences and long run growth (Acemoglu and Johnson 2005; Lloyd and Lee 2016). However, most research on the economic effects of institutions or social values examines the effects of these phenomena in isolation (Jordaan et al. 2016). Findings from the small number of studies that do examine economic effects of social values and institutions jointly show that this may impact upon the estimated effect of social values.

For instance, Tabellini's (2010) well-known finding that differences in cultural traits related to respect and self-confidence provide an important explanation for income differences between EU regions is based on estimating models that do not control for regional institutional differences. When replicating the econometric estimations for regions within Italy whilst controlling for both these cultural traits and the quality of regional governmental institutions, the effect of culture turns insignificant (see Tabellini 2010). Another example is Williamson and Mathers (2011), who estimate the growth effect of a first principle component variable of trust, self-determination, respect and obedience. Their findings show that the estimated positive effect of this cultural variable is smaller in countries with favourable institutional characteristics related to economic freedom. Mullings (2017) and Ahlerup et al. (2009) present similar findings that the effect of culture or social values is affected when the estimations also control for institutional country characteristics. Therefore, any estimation of the effects of social values such as post materialism on economic development needs to incorporate an assessment of the effect of institutions, not only as institutions generate separate economic effects but also because they may affect the estimated relation between post materialism and economic development.

Another interpretation of the evidence from research on the effects of social values and institutions is that social values may influence the functioning of institutions. This interpretation follows from the hierarchy of social analysis as proposed by Williamson (2000), in which customs, norms, traditions and other social values constitute the highest form of social analysis. The next level of analysis contains institutions, which are conditioned by social values. In line with this hierarchy, several studies examine how social values impact upon institutions (see Alesina and Giuliano 2015; Bidner and Francois 2010). A well-known example is Licht et al. (2007), who find that countries whose citizens value autonomy and egalitarianism are characterised by more democratic accountability and less corruption. 
Some studies examine whether and how elements of the concept of post materialism may impact upon institutions. Welzel and Inglehart (2005) use data from the World Values Survey to construct an index of postmaterialist liberty aspirations. This index is positively associated with indicators of civil and political freedom. In relation to this, Welzel et al. (2003) find that emancipative values foster democracy. Kravtovsa et al. (2017) report a robust negative association between the country level of post materialism and corruption measured by bribery disapproval. To understand these effects, it is important to recognise that post materialists are prone to be politically active in terms of voicing their opinions and exerting pressure on the political establishment to improve institutions (Welzel et al. 2003; Opp 1990; Copeland 2014).

Furthermore, the feature that post materialists value independence and autonomy may also impact upon institutions. Pitlik and Rode (2017) examine the relationship between individualism and government intervention and find that individualistic traits related to self-determination foster the creation of market friendly institutions. Allik and Realo (2004) and Welzel (2010) take a different approach by examining whether individualism and self-expression are detrimental to civil society. Their findings suggest this not to be the case, as self-expression exercises a positive effect on social trust (Welzel 2010) and on a more broadly measured indicator of social capital (Allik and Realo 2004).

Finally, a small but important literature is attempting to merge the literatures on the economic effects of social values and institutions and their interrelationship. Combining the evidence that social values and institutions generate economic effects with findings that social values influence or condition institutions suggests that institutions may act as transmission channel of (part of the) effects of social values. Only a limited number of studies have attempted to identify this transmission effect of institutions (Bjørnskov 2012). Jordaan et al. (2016) use 3SLS estimation techniques in their study on the effect of social values on financial development and find that a substantial part of the effect runs via various democratic and legal institutions. Boulila et al. (2008) estimate a simultaneous equation model on drivers of economic growth and find that social capital fosters growth via its positive effect on institutional quality. Bjørnskov (2012) conducts a similar study and finds that trust has a positive effect on growth via its effect on the rule of law. Bjørnskov and Méon (2015) provide the most extensive study on the role of institutions as transmission channel. Using 3SLS techniques they find that trust exercises a significant positive effect on productivity, an effect that runs mainly via economic and legal institutions.

\subsection{Research Questions}

Considering the growing prominence of post materialistic priorities and values and their structural differences with materialistic values, it is likely that post materialism impacts upon economic development. Therefore, our first research question is whether post materialism is significantly associated with economic development. Given that there are arguments favouring both positive and negative effects, the answer to this research question will also clarify the nature of the direct economic effect of post materialism. Second, when estimating the effect of post materialism, we need to control for the effect of institutions. As the literature review shows, not only do institutions create direct effects on economic development, they may also impact upon the economic effects of social values. Consequently, our second research question is whether post materialism and institutions both exercise significant direct economic effects. In extension of this, we also need to account for possible relationships between post materialism and institutions. In line with Williamson's (2000) 
notion that social values constitute a higher level of social analysis compared to institutions, it may be that post materialism impacts upon institutions. If so, this may create indirect economic effects running from post materialism via institutions. To investigate this, our third research question is whether institutions act as transmission channel of an indirect effect from post materialism onto economic development.

\section{Data, Model and Estimation Strategy}

\subsection{Data and Model}

To answer the research questions, we estimate a variety of specifications of the following regression model for a cross-section of countries:

$$
\left(\frac{G D P}{C a p}\right)_{i}=\beta_{0}+\beta_{1} \text { PostMaterialism }_{i}+\beta_{2} \text { Institutions }_{i}+\beta_{x} X_{i}+\varepsilon_{i}
$$

This models posits economic development of country i measured by Gross Domestic Product (GDP) per capita for 2014 as a function of post materialism, several institutional characteristics, a vector $\mathrm{X}$ containing a set of additional control variables and an idiosyncratic error term. Table 1 lists all the variables that we use in the analysis. We follow Hall and Jones (1999) in using as dependent variable GDP per capita rather than average growth of GDP per capita for two reasons. First, as Hall and Jones (1999) note, the variation of the level of GDP/Capita in a cross-section of countries captures differences in long run economic performance that are most directly linked to welfare measured by the consumption of goods and services. This welfare measure is likely to be influenced by post materialism which incorporates a decreasing importance of consumption-based welfare maximisation. Second, the slow changing nature of social values such as post materialism and institutions makes it difficult to identify their economic effects in panel data estimations with as dependent variable averaged annual growth of GDP per capita calculated for relative short time periods. The use of average growth rates of GDP per capita over longer time periods in cross-sectional estimations is also problematic, as growth rates over shorter time periods within such longer time periods are often only weakly correlated (e.g. Pritchett 2016; Berg et al. 2012).

Our selection of countries is driven primarily by data availability to construct indicators of post materialism. The information to calculate such indicators is freely available from the World Values Survey ${ }^{2}$ and the European Values Study. ${ }^{3}$ These international surveys have been conducted in several waves over the last decades, enquiring about a range of political, economic, cultural and social issues. Among the extensive list of topics, these surveys contain a set of two questions on national priorities of a country that are commonly used to calculate indicators of post materialism (see Inglehart 1977). Respondents that select as main national priorities "maintaining order" and "fighting rising prices" are classified as having materialistic values. Respondents that select both "giving people more

\footnotetext{
2 WORLD VALUES SURVEY 1981-2014 LONGITUDINAL AGGREGATE v.20150418. World Values Survey Association (www.worldvaluessurvey.org). Aggregate File Producer: JDSystems, Madrid SPAIN.

3 http://www.europeanvaluesstudy.eu; data obtained from the Leibniz Institute for the Social Scienceshttps://www.gesis.org/en/en/home/.
} 


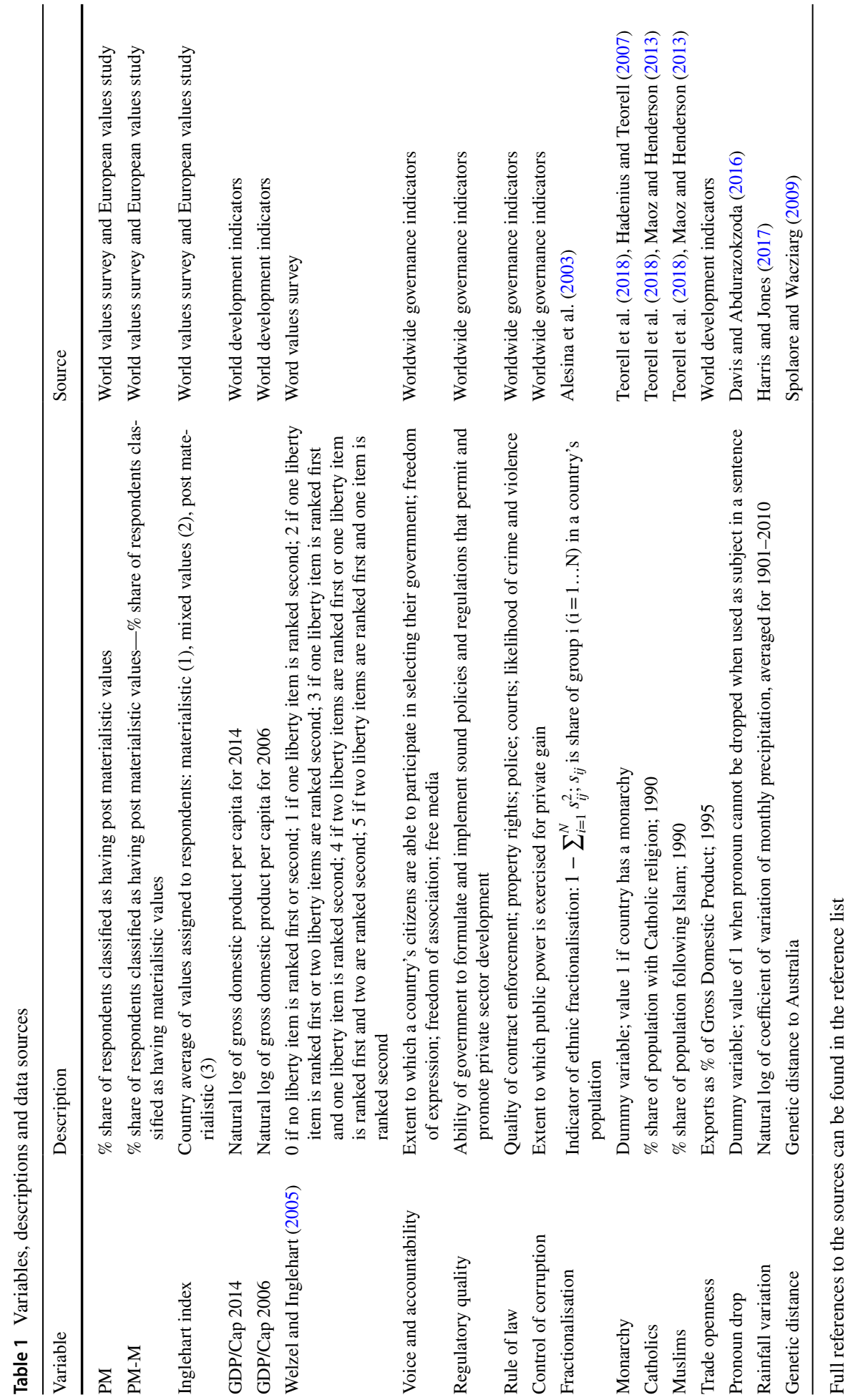




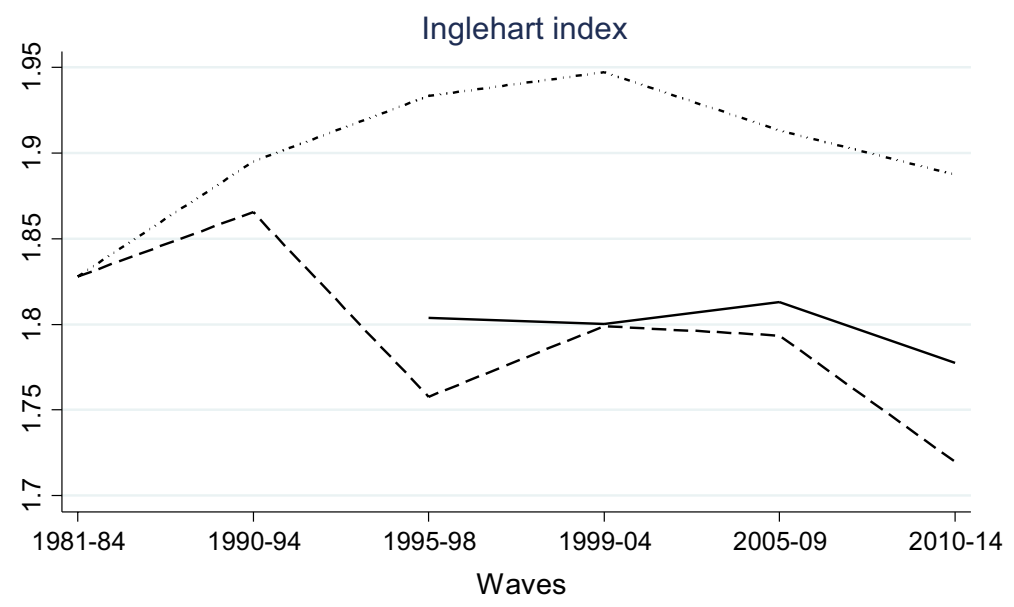

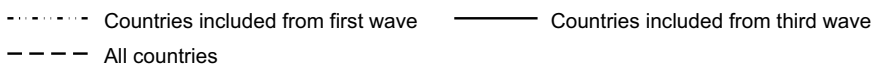

Fig. 1 Post materialism: various waves

say in important government decisions" and "protection of freedom of speech" are classified as having post materialistic values. Respondents that select both a materialistic and a post materialistic priority are classified as having mixed values.

Using this information, we calculate several indicators of the country-level of post materialism. One indicator, labelled "PM", is the share of post materialistic respondents in the total number of respondents in a country. The drawback of this indicator is that it captures the level of post materialism in isolation, not considering the values of the other respondents. A partial solution to this is to subtract the percentage share of respondents that hold materialistic values from the percentage of respondents with post materialistic values (Inglehart 1977). We label this variable "PM-M", representing the two types of respondents with contrasting values. A third indicator is the well-known and often used "Inglehart index" (Inglehart 1977), which also incorporates the relative importance of citizens with mixed values. To calculate this index, respondents with materialistic values are assigned a score of 1 , respondents with mixed values receive a score of 2 and post materialistic respondents are assigned a score of 3 . To obtain the country level score of the Inglehart index, the individual scores are aggregated and averaged across the respondents. ${ }^{4}$

Figure 1 shows the development of post materialism measured by the Inglehart index over the various survey waves. The dashed line shows how post materialism has developed for all the countries that participated in the various survey waves. The figure shows a clear increase in post materialism from the first to the second wave. From the second to the third wave, there is a marked decrease. To understand this change, it is important to consider that the number of countries covered by the surveys increased substantially with the third wave. As the level of post materialism was lower in the newly included countries, the overall level

\footnotetext{
4 Table A.1. in the Online Appendix lists all the countries in the sample with their scores on the three post materialism indicators.
} 


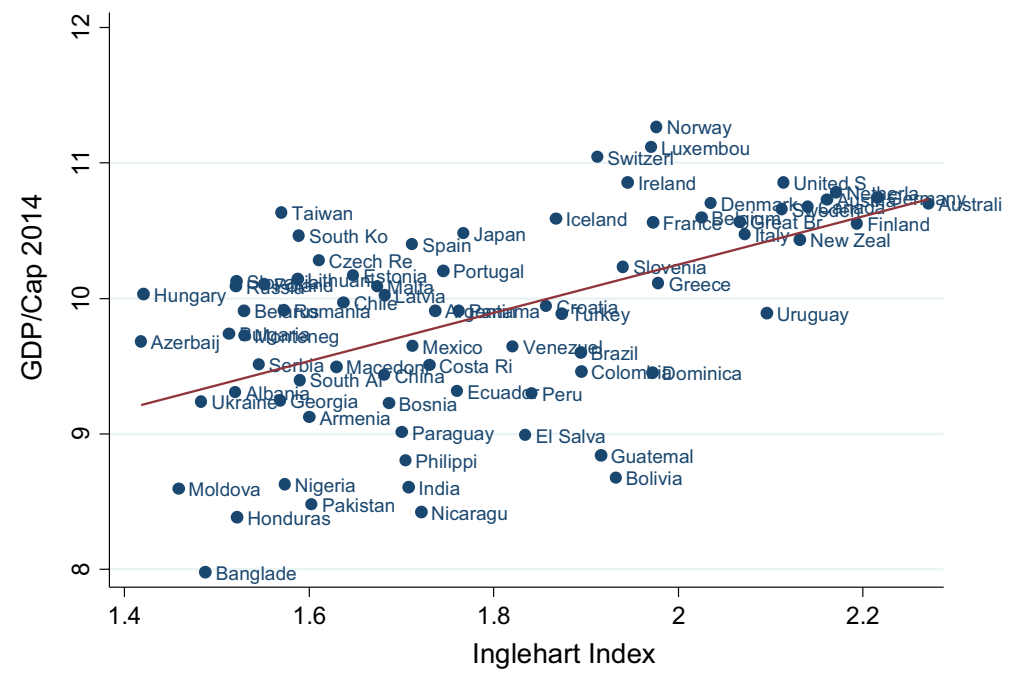

Fig. 2 GDP/Cap 2014 and Post Materialism

of post materialism for the entire group of countries decreased. ${ }^{5}$ The dotted line shows how post materialism has developed among those countries that were included from the first survey wave onwards. For this smaller set of countries, post materialism increased until up the beginning of the 2000s, after which there has been a decrease.

To have a sufficiently large sample of countries for our empirical analysis, we look at the level of post materialism in the third survey wave (1995-98). The fixed line in Fig. 1 shows how post materialism has developed for the countries included from the third wave onwards. Up until the fifth wave, these countries experienced a modest increase in post materialism. From the fifth to the sixth wave, there is a marked decrease in post materialism. An important explanation for this change is of course the financial crisis of 2007-2008, fostering an increased importance of income-related materialistic values. This drop in the level of post materialism is also clearly visible from the dashed line that uses the information from all the countries that participated in the various survey waves. For the group of countries included from the first wave onwards, the financial crisis caused the decrease in post materialism to continue. The implication for our empirical analysis of the change in the development of post materialism after the financial crisis is that we need to examine whether this change has impacted upon the relation between post materialism and economic development.

To obtain an impression of the relation between post materialism and the dependent variable, Fig. 2 contains a scatterplot between the Inglehart index and GDP/Cap in $2014 .^{6}$ The scatterplot shows a clear positive relationship, suggesting that post materialism fosters income per capita. Regarding the strength of the association, a bivariate regression of GDP/Cap 2014 on the Inglehart index produces a positively signed coefficient with the value 1.78 , significant at the $1 \%$ level with an R-squared of 0.29 . For PM and PM-M, the

\footnotetext{
${ }^{5} \mathrm{PM}$ and PM-M have developed in a similar way, as shown in Figure A.1 in the Online Appendix.

${ }^{6}$ Figure A.2 in the Online Appendix presents the scatterplots with PM and PM-M.
} 
estimated coefficients are 5.09 and 2.04 (both significant at the $1 \%$ level), with R-squared values of 0.34 and 0.36 .

The second set of control variables consists of several institutional country characteristics. The source of the institutional variables is the Worldwide Governance Indicators Project (WGIP). This project provides freely available indicators of institutional characteristics capturing political, economic, judicial and democratic dimensions and provides comprehensive coverage of the countries in our sample. The aggregate indicators are derived from an array of underlying data, obtained from public sector organisations, non-governmental organisations, commercial business information providers and household and firm level surveys. These data are used to calculate composite governance indicators in units of a standard normal distribution, with zero mean and a standard deviation of 1 . The composite indicators range roughly between -2.5 and 2.5 , with higher values indicating better functioning institutions. ${ }^{7}$

As discussed in the literature review, to obtain an accurate estimate of the effect of post materialism, we need to control in the estimations for the effect of institutions. Furthermore, we want to include those institutions that may potentially act as a transmission channel of an indirect effect of post materialism on economic development. Given this requirement, we focus on the following four institutional variables. The first variable is "voice and accountability", capturing aspects related to personal freedom, participation in elections and freedom of association. We include this variable given findings from Welzel and Inglehart (2005) and Welzel et al. (2003) that show that post materialists value personal freedom and democracy. Second, we include two variables related to the quality of regulation. One variable is labelled "regulatory quality", capturing the degree that governments are able to formulate and implement sound policies and regulations that promote private sector development. We also include "rule of law", referring to perceptions of the degree that citizens have confidence in and abide by the rules of society. Together, these two variables reflect an institutional framework that, within solid rules, promotes the existence of market friendly institutions. These variables are related to the finding that individualism or autonomy, values valued by post materialists, are positively associated with the existence and functioning of market friendly institutions (Pitlik and Rode 2017). The fourth institutional factor that we incorporate concerns the variable "control of corruption", indicating the degree to which public power is not exercised for private gain. We include this variable given that post materialists value autonomy and a small but well-functioning government, without the presence of corruption (Kravtovsa et al. 2017).

Finally, the vector $\mathrm{X}$ contains a set of additional control variables that may affect economic development. Specifying a parsimonious model, partly based on Hall and Jones (1999) and Ortega and Peri (2014), we include the following variables. The variable "fractionalisation" captures the degree of ethnolinguistic variation in the countries and is expected to exercise a negative effect (Alesina et al. 2003). The variable "monarchy" controls for the feature that countries with a monarchy tend to be characterised by a higher level of economic development (Wright 2008). Next, we control for the population shares of Muslims and Catholics to capture the feature that countries with relative high shares of these religions have lower levels of economic development compared to countries where Protestantism is more prominent (Guiso et al. 2006). We also include the degree of trade

${ }^{7}$ For a detailed explanation, see Kaufman et al. (2010). 
Table 2 Relation between institutions and post materialism

\begin{tabular}{lllll}
\hline Dependent variable & $\begin{array}{l}\text { Voice and } \\
\text { accountability }\end{array}$ & Regulatory quality & Rule of law & Control of corruption \\
\hline Inglehart index & $\begin{array}{l}2.38 * * * \\
(0.36)\end{array}$ & $\begin{array}{l}2.40 * * * \\
(0.34)\end{array}$ & $\begin{array}{l}2.91 * * * \\
(0.42)\end{array}$ & $\begin{array}{l}3.59 * * * \\
(0.44)\end{array}$ \\
F & 42.32 & 50.34 & 48.64 & 65.63 \\
Adj. R-square & 0.36 & 0.40 & 0.39 & 0.47 \\
N & 75 & 75 & 75 & 75 \\
\hline
\end{tabular}

$* * * p<0.01$; robust standard errors in parentheses

openness, measured by exports as percentage of GDP, to control for the positive effect of trade on GDP per capita (Frankel and Romer 1999).

\subsection{Estimation Strategy: Endogeneity of Post Materialism and Institutions}

The estimation of model (1) is based on the premise that post materialism and institutions influence economic development. However, it is well-known that income may also influence institutions and social values. Referring back to Fig. 2, the positive association between GDP/Capita 2014 and the Inglehart index is likely to capture an effect of post materialism on income per capita as well as an effect of income per capita on post materialism. The latter effect is caused by the feature that post materialistic values become more prominent when countries have reached a certain income level (Inglehart 1977). In a similar way, countries with a relative high level of income are in a better position to create better institutions or improve existing institutions (Tabellini 2008). Therefore, it is very likely that the estimated coefficients of model (1) are affected by endogeneity of the institutional and post materialism variables.

To deal with this, we resort to the use of IV estimation techniques. In our instrumentation strategy for the institutional variables we follow the approach that uses social values as instrument for institutions. This approach is in line with the theoretical considerations underlying the hierarchy of social analysis by Williamson (2000) and the empirical evidence that social values influence institutions (Alesina and Giuliano 2015). In particular, we use the degree of post materialism as instrument for institutions (see Jordaan et al. 2016). Citizens with post materialistic values are socially active and are likely to put pressure on governments to change and improve institutional settings, in order to advance their values and priorities. We can use this relation between post materialism and institutions to control for the endogenous component of the relation between institutions and income per capita. Table 2 reports the findings from bivariate regressions of the four institutional variables from the WGIP on the Inglehart index. ${ }^{8}$ For all four institutional variables, the estimations reveal a positive and significant effect of post materialism, suggesting that citizens with post materialistic values put pressure on institutions to improve.

Next, we follow Jordaan et al. (2016) in the selection of an instrument for the post materialism variable. They conduct an econometric study on the effect of post materialism on financial development measured by the size of stock markets, a relationship that is affected

${ }^{8}$ We obtain similar findings with the PM and PM-M variables. 
Table 3 Relation between post materialism and pronoun drop rule

\begin{tabular}{llll}
\hline Dependent variable & PM & PM-M & Inglehart index \\
\hline Pronoun drop rule & $-0.09^{* * *}$ & $-0.25^{* * *}$ & $-0.26^{* * * *}$ \\
& $(0.02)$ & $(0.05)$ & $(0.05)$ \\
F & 24.09 & 26.67 & 28.65 \\
Adj. R-square & 0.24 & 0.26 & 0.27 \\
N & 75 & 75 & 75 \\
\hline
\end{tabular}

$* * * p<0.01$; robust standard errors in parentheses

by a negative effect of the dependent variable on post materialism. As instrumental variable they use a variable that captures a core characteristic of the official language of the countries in their sample. This is in line with several other studies that use linguistic country characteristics to identify causal effects of social values (Licht et al. 2007; Tabellini 2008; Davis and Abdurazokzoda 2016).

The use of linguistic characteristics as instrument for social values is based on the language relativity hypothesis that posits that a language influences a person's perception of the world (Sapir 1970; Whorf 1956). Kashima and Kashima (1998) use this to examine the notion that grammatical rules of a language have an impact on the degree of individualism in a country. A language where the personal pronoun can be dropped when used as a subject in a sentence (e.g. Spanish) is more likely to be linked to a society that is characterised by a stronger emphasis on the collective. In contrast, societies in countries with languages where the pronoun in such a sentence cannot be dropped (e.g. English) are likely to attach a higher value to individualism. In their empirical analysis, Kashima and Kashima (1998) find clear evidence that this so-called pronoun drop rule is significantly associated with country level indicators of individualism. Davis and Abdurazokzoda (2016) provide further corroborating evidence of this association.

The link between this linguistic rule and the degree of individualism versus collectivism suggests that it can serve as an instrument for the post materialism variable (Jordaan et al. 2016). All else equal, a society with a higher degree of collectivism is likely to have a stronger presence of post materialistic collectivistic values including concerns for environmental protection and social equality. To test this, we use the pronoun drop rule variable from Davis and Abdurazokzoda (2016), who improve the Kashima and Kashima (1998) dataset and extend the number of countries. Their dataset contains a dummy variable taking the value of 1 when a country's language does not allow for the pronoun to be dropped when used as a subject in a sentence, capturing countries with a stronger emphasis on individualism. Table 3 reports the findings from bivariate regressions of the three post materialism indicators on the pronoun drop rule variable. The estimated significant and negative effect of the dummy variable in the three estimations indicates that countries with official languages that do not allow for the pronoun to be dropped are characterised by significantly lower levels of post materialism.

Combining the instrumentation of the post materialism indicators and the institutional variables results in the following system of equations that we can estimate with 3SLS techniques:

$$
\left(\frac{G D P}{C a p}\right)_{i}=\beta_{0}+\beta_{1} \text { PostMaterialism }_{i}+\beta_{2} \text { Institutions }_{i}+\beta_{x} X_{i}+\varepsilon_{i}
$$

$$
\text { Institutions }_{i}=\delta_{0}+\delta_{1} \text { PostMaterialism }_{i}+\gamma_{i}
$$




$$
\text { PostMaterialism }_{i}=\vartheta_{0}+\vartheta_{1} \text { PronoundDrop }_{i}+\mu_{i}
$$

The appealing feature of this system of equations is two-fold. By instrumenting both the post materialism and the institution variables, we ensure that we identify causal effects of these variables on the dependent variable, cleared from endogeneity concerns. Furthermore, by instrumenting the institutional variables with the post materialism variable, the findings will indicate whether the effect of post materialism on economic development is (partly) transmitted via institutions, shedding new light on the question whether institutions act as transmission channel of the economic effect of social values such as post materialism.

\section{Empirical Findings}

\subsection{Post Materialism and Economic Development}

We start the analysis by estimating the direct effect of post materialism on GDP/Capita. Table 4 presents the findings from estimating several specifications of regression model (1). The first three columns contain the findings from OLS estimations that include the indicators of post materialism and the other control variables whilst omitting the institutional country characteristics. All three indicators of the country level of post materialism carry positive and significant coefficients, suggesting that post materialism fosters economic development. ${ }^{9}$ However, as discussed in the previous section, it is difficult to interpret the estimated coefficients of the post materialism indicators as it is very likely that they incorporate a positive effect of the level of economic development on the degree of post materialism. The estimated effects of the other control variables are in line with expectations. The estimated negative effects of fractionalisation and the population shares of Catholics and Muslims are in line with the literature. The estimated positive effect of trade openness confirms the positive effect of trade on economic development. The estimated coefficient of the Monarchy variable carries the correct sign but is statistically insignificant.

The second set of columns contains the results when we instrument the post materialism variables with the pronoun drop rule variable. Judging from the first stage F, R-squared and Anderson under-identification statistics, the instrumentation of the post materialism variables functions satisfactorily. Looking at the estimated effect of post materialism with the IV estimator, the findings show coefficients that are larger than those obtained with the OLS estimations, although F-tests indicate that the differences are not statistically significant. ${ }^{10}$ Whereas post materialism may dampen the level of economic development due to the promotion of societal goals that are less geared towards production and income maximisation, it may also promote economic development by fostering individualism and economic freedom. The estimated positive effect of the instrumented post materialism variables suggests that on balance the positive economic effect of post materialism is larger

\footnotetext{
${ }^{9}$ We also estimated the models adding squared terms of the post materialism variables, following research on the economic effects of other social values that suggest that relations between social values and economic development may be characterised by non-linearity (Horvath 2013; Peiró-Palomino 2016). None of the squared post materialism terms carry significant coefficients in the present analysis, however.

${ }^{10} \mathrm{PM} \mathrm{F}=1.33$ (0.25); PM-M F = 1.23 (0.28); Inglehart index F=2.24 (0.13).
} 


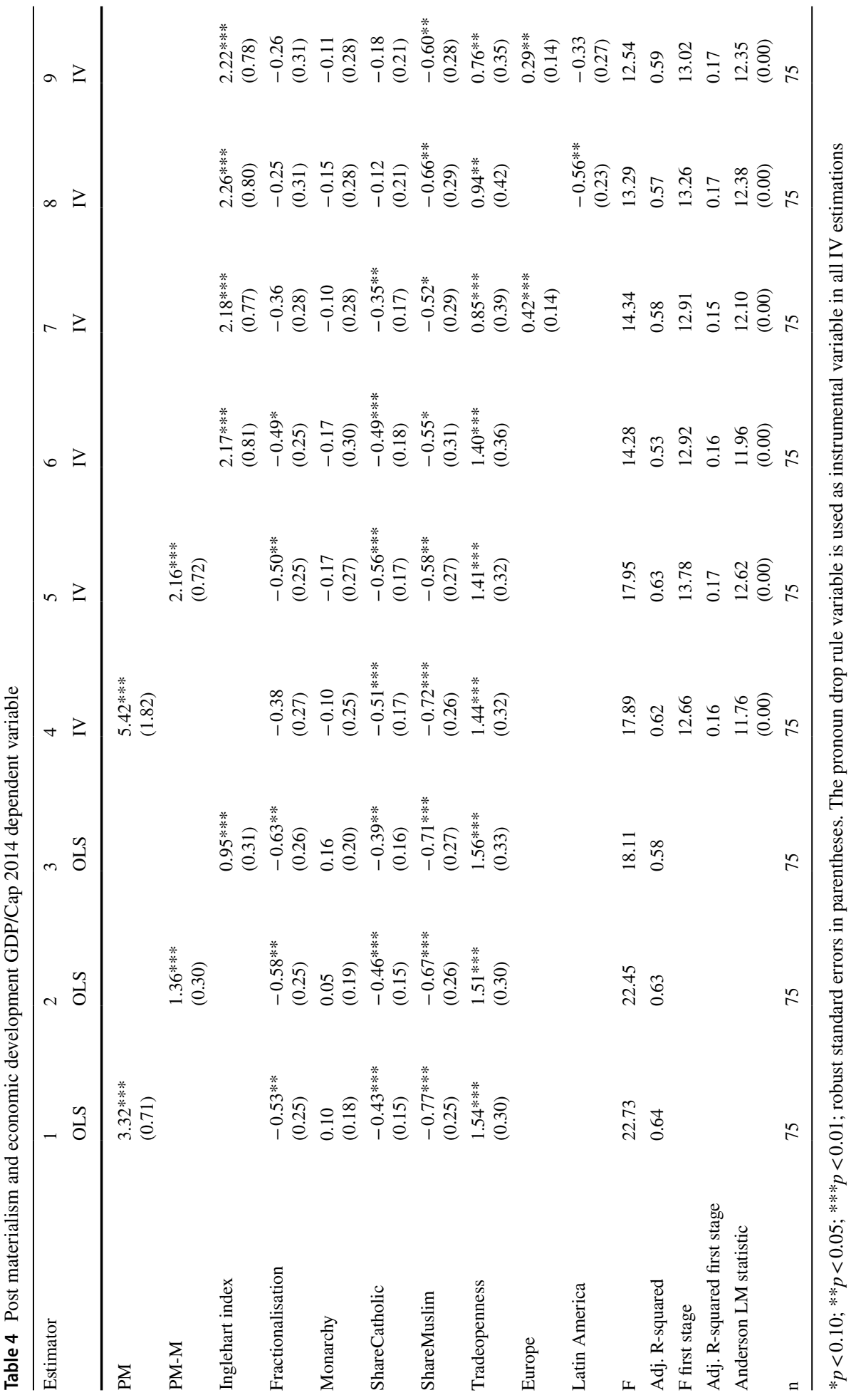


than its negative effect. Further on in the analysis we will assess whether the inclusion of the institutional variables to the model changes this finding. ${ }^{11}$

The final three columns contain the results from adding multi-country regional dummies to the regression model. As the model is parsimoniously specified, there is the issue that important variables may have been omitted from the model. To assess whether this impacts upon the estimated effect of post-materialism, we re-estimate the model adding dummy variables for Europe and Latin America, continents that are strongly represented in the sample. As the findings show, countries located in Europe have a structurally higher level of income per capita, whereas countries in Latin America have a structurally lower level of income per capita. Looking at the other control variables, the estimated effects of the variables capturing ethnic fractionalisation and the population share of Catholics turn insignificant, indicating that their effect is largely absorbed by the two continent dummies. Importantly, the estimated effect of the Inglehart index is unaffected by the inclusion of the two continent variables.

Before we continue with the analysis by estimating the system of equations that incorporates the effects of post materialism, institutions and their interrelationship, we conduct a set of additional estimations to assess the robustness of the estimated relation between post materialism and GDP/Capita as presented in Table 4. In particular, we estimate the model using GDP/Cap measured prior to the occurrence of the financial crisis, with an extended indicator of post materialism, on a restricted sample that omits former communist countries and with alternative instruments for the post materialism variables.

First, there has been a drop in the level of post materialism following the financial crisis of 2007-2008. Differences in the degree to which countries experienced and dealt with the effects of the financial crisis may have impacted upon their economic performance and may also have created changes in the relation between economic development and post materialism. To assess whether this is the case, we replace GDP/Cap measured for 2014 with GDP/Cap measured for 2006. Columns 1-3 in Table 5 presents the findings from using this alternative dependent variable. Compared to the findings with GDP/Cap 2014, the estimated effect of the three post materialism indicators is larger for the period prior to the financial crisis. However, $\mathrm{F}$ tests indicate that the differences between the estimated coefficients that are obtained from using GDP/Cap 2006 are not significantly different from the results with GDP/Cap 2014. ${ }^{12}$ This indicates that the estimated relation between post materialism and the level of economic development has not been affected by the financial crisis.

Second, we estimate the model using a different indicator of post materialism. This alternative indicator is based on Welzel and Inglehart (2005), who construct an indicator of post materialism that is geared towards capturing the degree of liberty aspirations incorporated into post materialistic values. Next to using the responses to the questions on what a country's first and second priority should be that underlie the calculation of the standard Inglehart index, they add another priority question regarding citizens' capacity to have

\footnotetext{
11 As a preliminary examination, Table A2 in the online appendix shows the findings from OLS estimations where we include both the Inglehart index and the individual institution variables in the regression model. The estimated effect of the institution variables is positive in all the estimations and their inclusion lowers the size of the estimated positive effect of post materialism on the level of economic development. This is in line with the studies that we discussed in section two that also find that the estimated economic effect of culture or social values is smaller when controlling for the effect of institutions.

12 PM F = 2.28 (0.13); PM-M F = 2.21 (0.14); Inglehart index F=2.59 (0.11).
} 


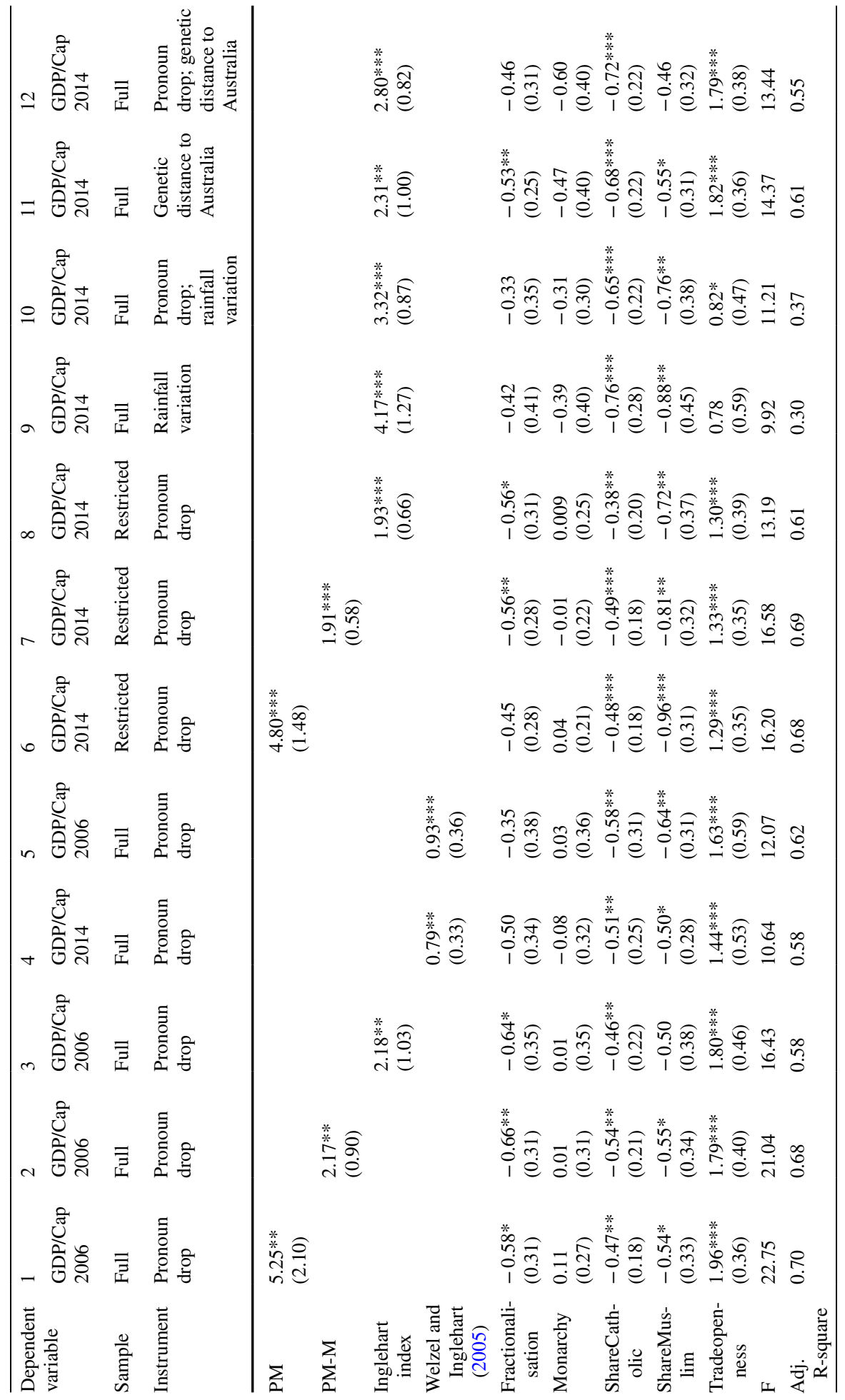




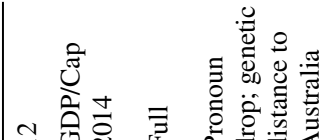

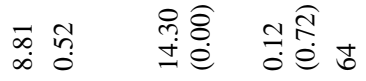

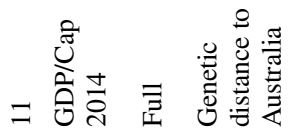

$\begin{array}{llll}\vec{b} & \stackrel{0}{0} & \overrightarrow{0} \\ \infty & \infty & \infty \\ 0 & \infty\end{array}$

仓ิ

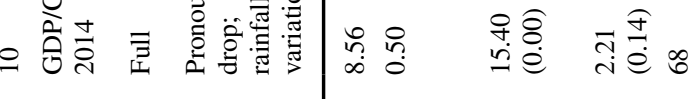

の

苍苞

त्ञ

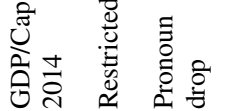

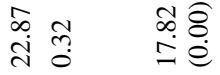

i

跣苞

?ำㅇ

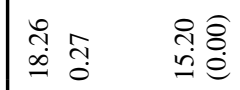

ํํㅇ

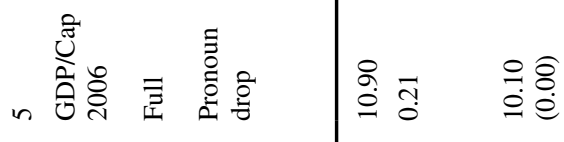

苍苍

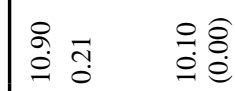

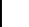

仓ี่

产

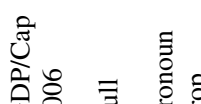

을 은

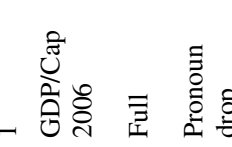

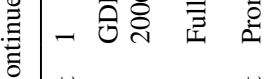

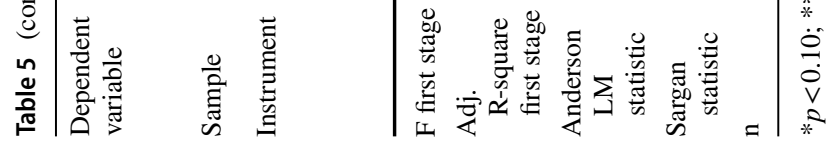

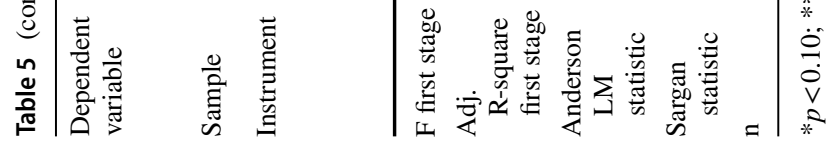

m.

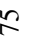

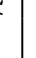

. 
more say in their jobs and their communities. Adding this information, they calculate an indicator of post materialistic liberty aspirations ranging from 0 to 5 , with 5 representing citizens prioritising all the post materialistic values. ${ }^{13}$ The drawback of this variable is that the additional question on country priorities is only available in the World Values Survey and not in the European Values Study, resulting in a substantial drop in the number of observations.

Columns 4 and 5 present the results from using the alternative post materialism indicator. The estimated effect of the alternative post materialism indicator is significant and positive, both for the models that use GDP/Cap 2014 and GDP/Cap 2006 as dependent variable. This is fully in line with the findings that we obtain with the Inglehart index. Although the Welzel and Inglehart (2005) indicator of post materialism is arguably more informative as it incorporates an additional post materialistic value, we prefer to use the more standard Inglehart index, as it is available for more countries and produces a similar effect.

Third, we estimate the model on a restricted sample. Setting aside the decrease in post materialism following the financial crisis, the overall impression is that there has been a steady increase in the level of post materialism in the world economy during the last decades. However, several countries in our sample consist of Eastern European and former communist countries. For these countries, the relationship between post materialism and economic development may be structurally different from the other countries in the sample, given the likelihood that concepts of materialism and post materialism were given different meanings when these countries were under communist regimes. Furthermore, the drastic and structural changes that these countries experienced since the fall of communism in the late 1980s may have impacted upon processes fostering materialistic and/or post materialistic values, which we measure in our analysis for the mid-1990s.

To assess whether the presence of former communist countries in the sample is affecting the estimated effect of post materialism, we estimate the regression model on a restricted sample that omits these former communist countries. As the results in Table 5 show, the findings with GDP/Cap 2014 as dependent variable with the restricted sample show coefficients of the post materialism variables that are smaller than for the full sample as presented in Table 4. However, the differences between the estimated effects of the post materialism indicators of the two sets of estimations are not significant, suggesting that any structural differences between former communist countries and the group of other countries in the sample do not influence the estimated relation between post materialism and economic development. ${ }^{14}$

Finally, we explore the relationship between post materialism and the level of economic development using different instruments. One alternative instrument is based on the link between climatic characteristics or climatic volatility and social values. A recent example of a study that investigates this link is Giuliano and Nunn (2017), who find that historical data capturing the stability of average temperatures is significantly associated with a preference for traditions and the persistence of cultural traits. Another example is provided by Davis (2016), who relates the historical variation of monthly rainfall to the relative importance of individualism versus collectivism, arguing that a higher level of rainfall variation increases agricultural risk and is therefore likely to foster collective responsibility (see also Nugent and Sanchez 1999). Davis's findings show a significant negative association

13 The variable is specified following Inglehart and Welzel (2005), as explained in Table 1 .
14 PM F=0.99 (0.32); PM-M F=0.91 (0.34); Inglehart index $F=2.19(0.14)$. 
between rainfall variation and the importance of individual responsibility, indicating that weather volatility is related to this particular type of social value.

We use the rainfall variation variable as specified by Davis (2016) to instrument for the country level of post materialism. Post materialists value autonomy and independence and as such can be thought to rate individual responsibility. This suggests that societies that experience a lower variation in rainfall will be more characterised by individual responsibility, in line with post materialistic values related to economic independence and autonomy. To calculate the rainfall-based instrument, we use the CRU CY4.01 dataset from the University of East Anglia Climatic Research Unit (Harris and Jones 2017). This dataset contains monthly precipitation levels for most of the countries in our sample. Following Davis (2016), we calculate for each country the natural log of the average coefficient of variation of yearly intertemporal rainfall and then compute averages for the period 1901-2010.

Columns 9 and 10 report the findings from instrumenting the Inglehart index with the rainfall variation instrumental variable or with both the rainfall variation variable and the pronoun drop rule variable, using GDP/Cap 2014 as dependent variable. The estimated effect of the Inglehart index persists to be positive and is significantly larger than the effect that we obtain when using the pronoun drop rule variable as instrument. The first stage statistics indicate that the instrument based on rainfall variation functions satisfactorily. The $p$ value of the Sargan statistic reported in column 10 from the estimation where we use both instruments shows that the overidentifying restrictions cannot be rejected, indicating that the instruments are appropriate. A drawback of the use of the rainfall variation instrumental variable is that the R-square of the second stage of the estimation is substantially lower compared to the estimation that is based on the pronoun drop rule instrumental variable. In any case, the use of the alternative instrument does confirm the significant and positive association between post materialism and GDP per capita.

The other alternative instrument that we use is linked to research that uses insights from research on population genetics to identify drivers of economic development. Spolaore and Wacziarg (2009) use data from Cavalli-Sforza et al. (1994) to calculate an indicator of international genetic distances. Cavalli-Sforza et al. (1994) use information from a set of genes to calculate genetic differences between 42 world population groups. Combining this data with information on the distribution of these population groups over the countries in the world economy, Spolaore and Wacziarg (2009) construct a dataset capturing genetic distances between countries. ${ }^{15}$ They interpret their indicator of genetic distance as a 'summary statistic capturing divergence in the whole set of implicit beliefs, customs, habits, biases, conventions, etc. that are transmitted across generations-biologically and/or culturally' (Spolaore and Wacziarg 2009, p. 471). ${ }^{16}$ In their estimations, they find that genetic distances are significantly associated with international income differences. They explain their findings by arguing that countries that are genetically close to the world technological frontier (the United States) find it easier to adopt new knowledge and technologies, as

\footnotetext{
15 The genes that underlie the distance measure are neutral, in the sense that they change randomly and are not influenced by selection pressure. This means that the measure of genetic distance only constitutes an indicator of the lines of descent between the population groups and is not related to genetic differences that may relate to survival or fitness of any of the various population groups (see Spolaore and Wacziarg 2009).

16 This is corroborated by Desmet et al. (2006), who find a positive and robust relation between international genetic and cultural distances, where the latter type of distance is measured by a long range of questions from the World Values Survey on life, family, religion and morals.
} 
genetic proximity suggests that countries contain deep underlying social and cultural traits that facilitate the adoption of such new technologies.

Based on the interpretation by Spolaore and Wacziarg (2009) that the genetic distance between countries captures intrinsic cultural differences, we can use genetic distances as an instrument for the country level of post materialism. ${ }^{17}$ To do so, we take the country with the highest level of post-materialism in the dataset-Australia—as representing the world frontier of post materialistic values. We then use the dataset from Spolaore and Wacziarg (2009) to calculate the genetic distance between Australia and the other countries in the sample and use this genetic distance between the countries and Australia as instrumental variable for post materialism. This approach is based on the assumption that when the genetic structure of the Australian population fosters a high level of post materialism, countries that are genetically close to Australia should also have a relative high level of post materialism.

The findings from using the genetic distance variable or both the genetic distance variable and the pronoun drop rule variable as instruments are presented in columns 11 and 12. We obtain findings similar to the other estimations, with the Inglehart index carrying a significant and positive coefficient. The magnitude of the estimated effect is very similar to the effect obtained for the full sample of countries with the pronoun drop rule as instrumental variable as reported in Table 4. The Sargan statistic reported in column 12 from the IV estimation using both instruments indicates that the over identifying restrictions cannot be rejected, suggesting that the instruments as a set are exogenous.

\subsection{Post Materialism, Institutions and Economic Development}

The findings in the previous section provide evidence that there is a significant and positive association between post materialism and GDP per capita, an association that appears robust to sample composition, time frame, choice of post materialism indicator and choice of instrumental variable. To assess whether the estimated effect of post materialism is affected by the inclusion of variables that capture key institutional characteristics and by the interrelationship between post materialism and institutions, we proceed by estimating the system of Eqs. 2a-2c for each of the individual institutional variables. The findings for the key variables of interest are presented in Table 6 . We report the estimated coefficients from the first, second and third stage of the estimations together with the goodness of fit for each of the stages. As the results show, in the first stage the pronoun-drop rule is significantly associated with the Inglehart index, which in turn is significantly associated in the second stage with the various institutional indicators.

The top left of Table 6 contains the findings from estimating the system of equations that controls for the effect of voice and accountability. The results contain three important features. First, in strong contrast to the findings in Tables 4 and 5, the third stage findings indicate that the effect of post materialism has turned negative. This is in line with the argument that post materialism dampens the level of economic development as it attaches less importance to production and income maximisation. This change in estimated effect is also in line with the small set of studies that were discussed in the literature review that find that the inclusion of controls of institutional country characteristics can impact upon the estimated economic

\footnotetext{
17 In a similar way, Guiso et al. (2009) use genetic distance between countries as instrument for the level of trust between countries in their analysis of determinants of international trade patterns. Proto and Oswald (2016) link the genetic distance between countries to differences in national happiness.
} 


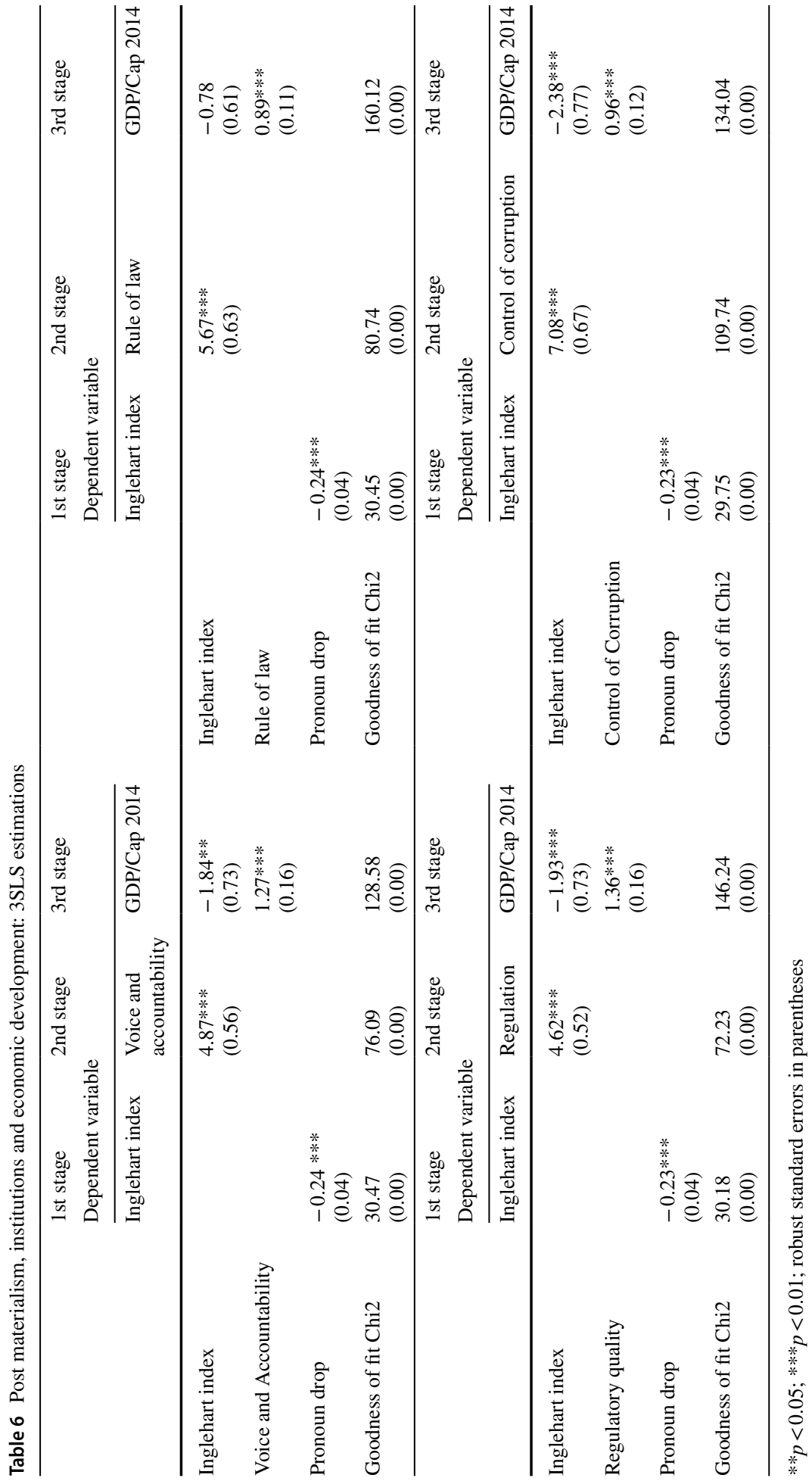


effect of social values. Second, the estimated effect of the variable of voice and accountability is significant and positive, in line with the common finding in the literature that institutions foster economic development. Third, given that we instrument voice and accountability in the system of equations with the post materialism variable, the estimated positive effect of the institutional variable also confirms that voice and accountability acts as a transmission channel of an indirect effect of post materialism on economic development. The explanation for this indirect effect is that citizens with post materialistic values put pressure on governments and society to improve institutions in order to advance their values and priorities.

Looking at the results of the estimations with the other institutional variables, the findings with regulatory quality and control of corruption are similar to the results that we obtain with voice and accountability. In both cases, the direct economic effect of post materialism is negative, whereas the effect of the institutional variables is positive. Looking at the size of the estimated coefficients suggests that the direct negative effect of post materialism is the strongest when using control of corruption as institutional variable. The institutions of regulatory quality and voice and accountability create the largest positive effects. The estimated effect of post materialism turns insignificant when controlling for rule of law as institutional force, suggesting that in this estimation the entire effect of post materialism consists of an indirect effect that runs via this institution.

To assess the robustness of these findings, we estimate the system of equations for all the differently specified models that underlie the findings in Table 5 . The findings from this additional set of estimations are presented in table A.3 in the Online Appendix. Overall, the findings are similar to those presented in Table 6. In all estimations, the significant direct positive effect of the institutional variables is confirmed. Similarly, the estimated effect of the post materialism variable is always negative, although the effect turns insignificant when using the Welzel and Inglehart (2005) post materialism indicator or with rainfall variation as alternative instrumental variable. The use of genetic distance as alternative instrument for the post materialism variable produces estimated positive effects of the institutional variables and negative effects from post materialism that are larger than those that we obtain with the pronoun drop rule instrumental variable.

The limitation of the findings is that although they confirm that institutions act as transmission channel of an indirect effect of post materialism on economic development, we cannot assess the relative size of this indirect effect. The findings in Tables 4 and 5 present the direct effect of post materialism without accounting for its effect on institutions. The findings in Table 6 present the direct effect of post materialism after taking out its indirect effect that runs via institutions. To obtain an indicator of the relative importance of the full and indirect effects of post materialism, we use the approach of residual generated regressors (Pagan 1984; Gomanee et al. 2005; Jordaan et al. 2016). To do so, we adjust the system of equations in the following manner. We regress the institutional variables on the Inglehart index:

$$
\text { Institutions }_{i}=\delta_{0}+\delta_{1} \text { PostMaterialism }_{i}+\gamma_{i}
$$

the residuals of this estimation contain the part of the variation of institutions that is unexplained by post materialism. The full equation that we estimated for Table 6 is:

$$
\left(\frac{G D P}{C a p}\right)_{i}=\beta_{0}+\beta_{1} \text { PostMaterialism }_{i}+\beta_{2} \text { Institutions }_{i}+\beta_{3} X_{i}+\varepsilon_{i}
$$

Substituting (3a) into (3b) gives: 
Table 7 Direct and total effect of post materialism on economic development

\begin{tabular}{|c|c|c|c|c|}
\hline & \multicolumn{2}{|l|}{ GDP/Cap 2014} & \multicolumn{2}{|c|}{ GDP/Cap 2006} \\
\hline & $\begin{array}{l}\text { Direct effect } \\
\text { Inglehart index } \\
\left(\beta_{1}\right)\end{array}$ & $\begin{array}{l}\text { Total effect } \\
\text { Inglehart index } \\
\left(\beta_{1}+\beta_{3} \delta_{1}\right)\end{array}$ & $\begin{array}{l}\text { Direct effect } \\
\text { Inglehart } \\
\text { index }\left(\beta_{1}\right)\end{array}$ & $\begin{array}{l}\text { Total effect } \\
\text { Inglehart index } \\
\left(\beta_{1}+\beta_{3} \delta_{1}\right)\end{array}$ \\
\hline \multicolumn{5}{|l|}{ Dependent variable 3 rd stage } \\
\hline Voice and accountability & $\begin{array}{l}-1.84^{* * *} \\
(0.73)\end{array}$ & $\begin{array}{l}2.89 * * * \\
(0.34)\end{array}$ & $\begin{array}{l}-1.43^{* *} \\
(0.75)\end{array}$ & $\begin{array}{l}3.33 * * * \\
(0.37)\end{array}$ \\
\hline Regulatory quality & $\begin{array}{l}-1.93 \text { *** } \\
(0.73)\end{array}$ & $\begin{array}{l}2.74 * * * \\
(0.32)\end{array}$ & $\begin{array}{l}-1.75^{* *} \\
(0.79)\end{array}$ & $\begin{array}{l}3.28 * * * \\
(0.35)\end{array}$ \\
\hline Rule of law & $\begin{array}{l}-0.78 \\
(0.61)\end{array}$ & $\begin{array}{l}2.69 * * * \\
(0.31)\end{array}$ & $\begin{array}{l}-0.25 \\
(0.65)\end{array}$ & $\begin{array}{l}3.16 \text { *** } \\
(0.33)\end{array}$ \\
\hline Control of corruption & $\begin{array}{l}-2.38 * * * \\
(0.77)\end{array}$ & $\begin{array}{l}2.64 * * * \\
(0.32)\end{array}$ & $\begin{array}{l}-1.97 * * \\
(0.84)\end{array}$ & $\begin{array}{l}3.10 * * * \\
(0.35)\end{array}$ \\
\hline
\end{tabular}

$* * p<0.05$; *** $p<0.01$; robust standard errors in parentheses; Direct effects are from estimating system of Eqs. 2a-2c; Total effects are from estimating system of Eqs. 3a-3c

$$
\left(\frac{G D P}{C a p}\right)_{i}=\left(\beta_{0}+\beta_{2} \delta_{0}\right)+\left(\beta_{1}+\beta_{2} \delta_{1}\right) \text { PostMaterialism }_{i}+\beta_{2} \gamma_{i}+\beta_{3} X_{i}+\varepsilon_{i}
$$

where the Inglehart index is instrumented with the pronoun drop rule variable. The estimation of (3b) and (3c) gives similar results for the control variables, except for the estimated effect of the post materialism variable. In Eq. $3 c,\left(\beta_{1}+\beta_{2} \delta_{1}\right)$ captures the full effect of post materialism on economic development, consisting of a direct effect $\beta_{1}$ and an indirect effect $\beta_{2} \delta_{1 \cdot}{ }^{18}$

The findings from estimating Eq. (3c) are presented in Table 7. We report the findings from models with GDP/Cap 2014 or GDP/Cap 2006 as dependent variable. Looking first at the results for the full period, the estimated full (direct + indirect) effect of post materialism is significant and positive. This means that the indirect effect of post materialism that runs via institutions is positive and larger than the direct negative economic effect of post materialism as reported in Table 6. Therefore, the overall effect of post materialism is positive, suggesting that the positive economic effect that is caused by post materialists putting pressure on institutions to improve is larger than the dampening economic effect related to the promotion of non-materialistic societal goals. Looking at the total positive effect of post materialism obtained with the different institutional variables, the findings suggest that this effect is the largest when accounting for the relationship between post materialism and the institution of voice and accountability. The differences of the estimated effect of post materialism between the models with the different institutional variables are modest, however, which is likely to be caused by the high degree of correlation between the institutional indicators from the WGIP. As for the findings with GDP/Cap 2006 as dependent variable,

18 The effect of institutions is captured by $\beta_{2} \gamma_{i}$ 
Table 8 Magnitude of effect on GDP/Cap 2014 of change in post materialism and institutions

\begin{tabular}{ccc}
\hline Control variables & $\begin{array}{c}\text { Change GDP/Cap in } \\
\text { response to one } \\
\text { standard deviation } \\
\text { change of control } \\
\text { variable }\end{array}$ & $\begin{array}{c}\text { Change } \\
\text { GDP/Cap } \\
\text { expressed as } \% \\
\text { of one standard } \\
\text { deviation of } \\
\text { GDP/Cap }\end{array}$ \\
\hline Post materialism & & \\
Total effect & 0.65 & 0.87 \\
Direct effect & -0.41 & -0.55 \\
Voice and accountability & 1.12 & 1.50 \\
\hline Post materialism & & \\
Total effect & 0.61 & 0.82 \\
Direct effect & -0.43 & -0.58 \\
Regulatory quality & 1.14 & 1.53 \\
\hline Post materialism & & 0.81 \\
Total effect & 0.60 & 0 \\
Direct effect & 0 & 1.32 \\
Rule of law & 0.98 & 0.79 \\
\hline Post materialism & & -0.71 \\
Total effect & 0.59 & 1.49 \\
Direct effect & -0.53 & \\
Control of corruption & 1.12 & \\
\hline
\end{tabular}

Calculations based on estimated coefficients as reported in Table 7 (Post materialism) and Table 6 (Institutions)

overall the estimated total effect of post materialism is higher, but the differences with the results for the full period are modest. ${ }^{19}$

Finally, we use the estimated coefficients from Tables 6 and 7 to obtain an indicator of the relative importance of the direct and total effects from post materialism and the direct effects from institutions. We calculate the effects on the dependent variable from a one standard deviation increase of post materialism and institutions and relate these changes to a one standard deviation of the dependent variable. The results are presented in Table 8 . The estimated direct negative effect of post materialism causes a decrease in GDP/Cap of between -0.55 and -0.71 standard deviation when the estimation controls for the effect of voice and accountability, regulatory quality or control of corruption. As reported earlier, when controlling for rule of law, the direct effect of post materialism turns insignificant.

19 Table A.4 in the Online Appendix reports the findings on the direct and total economic effects from post materialism obtained from the additional estimations. By and large, the findings from these additional estimations are in line with the findings presented in Table 7. In all estimations, the total effect of post materialism is positive and larger than the estimated negative direct effect of post materialism. Although the differences are small, most estimations show that the total effect from post materialism is the largest when accounting for an indirect effect that runs via the institution of voice and accountability. Similar to Table 7 , the estimated direct effect of post materialism is insignificant in several estimations when accounting for the effect of rule of law. This is also the case for the estimations that use the Inglehart and Welzel (2005) indicator of post materialism or rainfall variation as instrumental variable. 
The total positive effect of post materialism lies between 0.79 and 0.87 standard deviation increase of GDP/Cap, with the largest positive effect occurring when the estimation controls for the effect of voice and accountability. The positive effect of institutions is larger, with a one standard deviation increase creating an increase in GDP/Capita of around 1.5 standard deviations. The increase is smaller in the case of rule of law, with an increase in the dependent variable of 1.3 standard deviations. Overall, these findings clearly indicate that both post materialism and institutions create economically meaningful effects on the level of economic development.

\section{Summary and Conclusions}

Research on drivers of international income differences is increasingly focused on identifying the effects of fundamental causes of economic development. Important strands in this research field provide a range of econometric evidence that institutions and social values play important roles as fundamental causes of long run growth. In this paper, we conduct an empirical study that extends upon this research in two ways. First, we examine the economic effect of post materialism, a type of social value that has been largely overlooked in research on social values as fundamental cause of economic development. This omission is important, given that the growing prevalence of post materialistic societal goals and personal values and priorities is likely to exercise important effects on economic behaviour and outcomes. Second, most studies estimate for the economic effects of either social values or institutions, thereby introducing potential biases. One issue is that estimated effects of social values or institutions are likely to be affected by omitted variable bias when estimations control for only one of the two factors. Another issue is that, by separating research into the economic effects of institutions or social values, potential additional effects that can arise through their interrelationships remain unidentified. In this paper, we conduct a cross-country econometric study that addresses these issues, by estimating the effects of post materialism and institutions on economic development and by investigating whether institutions act as transmission channel of an indirect effect of post materialism.

The empirical specifications and identification strategy that we follow in the paper generate certain limitations. By estimating the economic effects of post materialism and institutions on GDP/Capita, we focus on long run international income differences. Therefore, our analysis does not consider the impacts that institutions and post materialism may generate on more dynamic processes of economic growth within shorter time frames, nor do we allow for possible effects that changes in post materialism and institutions may generate. Also, our choice to examine possible interrelationships between post materialism and institutional indicators from the WGIP limits somewhat the degree to which we are able to assess which institutional features are most prominent in being related to post materialism and transmitting its indirect economic effect. A closer examination of indicators of particular types of institutions may also help in clarifying under which conditions the total effect of post materialism is maximised. Regarding the latter factor, more work is also required on developing a better understanding of how the concept of post materialism has developed within the broader process of post modernisation and to assess whether and how post materialism is related to proximate causes of economic growth such as physical and human capital accumulation. We acknowledge these caveats of the present analysis and interpret them as avenues for future research. 
Focusing on the results of the present analysis, our main findings can be summarised as follows. First, we obtain clear evidence that post materialism is significantly associated with economic development. This association is robust to the use of several instrumental variables, different time frames, sample composition and several indicators of post materialism. As such, the findings indicate that post materialism should be added to the collection of types of social values that the literature considers as potential fundamental causes of economic development. The last decades have witnessed broad and structural processes of socio-economic change, where growing numbers of citizens are substituting non-materialistic for materialistic societal priorities and goals whilst also attaching greater importance to personal freedom, autonomy and self-expression. The growing importance of these changes, together with the findings in the present paper, strongly suggest that more research into the economic effects of post materialism is called for.

Second, our findings indicate the importance of examining the economic effects of social values and institutions jointly. When we omit institutions from the regression model, we identify a significant and positive direct economic effect of post materialism, across the range of estimations. However, when we include controls for the economic effects of institutions, the estimated direct effect of post materialism turns negative. This structural difference in estimated effect is indicative of the bias that can arise when estimating the economic effect of social values whilst not accounting for the economic effect of institutions.

Third, our findings provide clear indications that institutions act as transmission channel of an indirect effect of post materialism. More precisely put, we find that whereas the direct economic effect of post materialism is negative, its indirect effect that runs via institutions related to personal freedom, a solid regulatory framework and low corruption is positive. Importantly, a comparison of the direct and total effects of post materialism shows that the positive indirect effect is larger than its direct negative effect. This suggests that citizens with post materialistic values put pressure on governments and other organisations to improve institutions to further advance their personal values and priorities. When doing so, this pressure on institutions generates positive effects on economic development, effects that are larger than the direct negative economic effect caused by the growing prominence of societal goals that are less motivated by income and profit maximisation. In more general terms, our findings on the direct and indirect effects of post materialism and the effects of institutions indicate the importance of accounting for the interrelationship that may exist between social values and institutions, in order to ensure that their effects on economic behaviour and outcomes are identified in a more comprehensive way.

Acknowledgements We would like to thank the editor, two anonymous referees, Antoon Spithoven and participants of the 2017 WINIR Institutions \& Open Societies Conference in Utrecht for their valuable comments and suggestions. The usual disclaimers apply and all remaining errors are ours.

Open Access This article is distributed under the terms of the Creative Commons Attribution 4.0 International License (http://creativecommons.org/licenses/by/4.0/), which permits unrestricted use, distribution, and reproduction in any medium, provided you give appropriate credit to the original author(s) and the source, provide a link to the Creative Commons license, and indicate if changes were made. 


\section{References}

Abramson, P. R. (2011). Critiques and counter-critiques of the postmaterialism thesis: Thirty-four years of debate. Irvine, CA: Centre for the Study of Democracy, University of California at Irvine. Retrieved from http://escholarship.org/uc/item/3f72v9q4.

Abramson, P. R., \& Inglehart, R. (1995). Value change in global perspective. Ann Arbor: University of Michigan Press.

Acemoglu, D., \& Johnson, S. (2005). Unbundling institutions. Journal of Political Economy, 113(5), 949-995.

Acemoglu, D., Johnson, S., \& Robinson, J. (2005). Institutions as a fundamental cause of long-run growth. In P. Aghion \& S. N. Durlauf (Eds.), Handbook of Economic Growth, Chapter 6. Amsterdam: Elsevier.

Aghion, P., Algan, Y., Cahuc, P., \& Schleifer, A. (2010). Regulation and distrust. The Quarterly Journal of Economics, 125(3), 1015-1049.

Ahlerup, P., Olsson, O., \& Yanagizawa, D. (2009). Social capital vs institutions in the growth process. European Journal of Political Economy, 25, 1-14.

Akçomak, S., \& ter Weel, B. (2009). Social capital, innovation and growth: Evidence from Europe. European Economic Review, 53(5), 544-567.

Alesina, A., Devleeschauwer, A., Easterly, W., Kurlat, S., \& Wacziarg, R. (2003). Fractionalisation. Journal of Economic Growth, 8(2), 155-194.

Alesina, A., \& Giuliano, P. (2015). Culture and institutions. Journal of Economic Literature, 53(4), 898-944.

Allik, J., \& Realo, A. (2004). Individualism-collectivism and social capital. Journal of Cross-Cultural Psychology, 35(1), 29-49.

Berg, A., Ostry, J. D., \& Zettelmeyer, J. (2012). What makes growth sustained? Journal of Development Economics, 98(2), 149-166.

Beugelsdijk, S., \& van Schaik, T. (2005). Social capital and growth in European regions: An empirical test. European Journal of Political Economy, 21(2), 301-324.

Bidner, C., \& Francois, P. (2010). Cultivating trust: Norms, institutions and the implications of scale. The Economic Journal, 121, 1097-1129.

Bjørnskov, C. (2012). How does social trust affect economic growth? Southern Economic Journal, 78(4), 1346-1368.

Bjørnskov, C. (2017). Social trust and economic growth. In E. M. Uslaner (Ed.), Oxford handbook of social and political trust. ISBN: 9780190274801. Available at SSRN: http://dx.doi.org/10.2139/ ssrn.2906280.

Bjørnskov, C., \& Méon, P.-G. (2015). The productivity of trust. World Development, 70, 317-331.

Boulila, G., Bousrih, L., \& Trabelsi, M. (2008). Social capital and economic growth: Empirical investigations on the transmission channels. International Economic Journal, 22(3), 399-417.

Cavalli-Sforza, L. L., Menozzi, P., \& Piazza, A. (1994). The history and geography of human genes. Princeton, NJ: Princeton University Press.

Copeland, L. (2014). Value change and political action: Postmaterialism, political consurism, and political participation. American Politics Research, 42(2), 257-282.

Davis, L. S. (2016). Individual responsibility and economic development: Evidence from rainfall data. Kyklos, 69(3), 426-470.

Davis, L. S., \& Abdurazokzoda, F. (2016). Language, culture and institutions: Evidence from a new linguistic dataset. Journal of Comparative Economics, 44(3), 541-561.

Davis, L. S., \& Williamson, C. R. (2016). Culture and the regulation of entry. Journal of Comparative Economics, 44, 1055-1083.

De Haan, J., Lundström, S., \& Sturm, J.-E. (2006). Market-oriented institutions and policies and economic growth: A critical survey. Journal of Economic Surveys, 20(2), 157-191.

Delhey, J. (2010). From materialist to post-materialist happiness? National affluence and determinants of life satisfaction in cross-national perspective. Social Indicators Research, 97(1), 65-84.

Desmet, K., Le Breton, M., Ortuño-Ortín, I., \& Schlomo, W. (2006). Nation formation and genetic diversity. CEPR Discussion Papers, No. 5918. London: Centre for Economic Policy Research.

Doucouliagos, C., \& Ulubasoglu, M. A. (2006). Economic freedom and economic growth: Does specification make a difference? European Journal of Political Economy, 22(1), 60-81.

Edwards, M. S., \& Patterson, D. (2009). The influence of cultural values on economic growth: An expanded empirical investigation. The Journal of Political Science, 37, 148-173.

Fairbrother, M. (2013). Rich people, poor people, and environmental concern: Evidence across nations and time. European Sociological Review, 29(5), 910-922. 
Frankel, J. A., \& Romer, D. (1999). Does trade cause growth? The American Economic Review, 89(3), 379-399.

Giuliano, P., \& Nunn, N. (2017). Understanding cultural persistence and change. NBER working paper series, Paper No. 23617, Cambridge, MA: National Bureau of Economic Research.

Gomanee, K., Girma, S., \& Morissey, O. (2005). Aid and growth in Sub-Saharan Africa: Accounting for tranmission mechanisms. Journal of International Development, 17, 1055-1075.

Gorodnichenko, Y., \& Roland, G. (2011). Culture, institutions and economic development: Which dimensions of culture matter for long run growth? American Economic Review: Papers and Proceedings, 101(3), 492-498.

Gorodnichenko, Y., \& Roland, G. (2017). Culture, institutions and the wealth of nations. The Review of Economics and Statistics, 99(3), 402-416.

Granato, J., Inglehart, R., \& Leblang, D. (1996). The effect of cultural values on economic development: Theory, hypotheses and some empirical tests. American Journal of Political Science, 40(3), 607-631.

Guiso, L., Sapienza, P., \& Zingales, L. (2004). The role of social capital in financial development. The American Economic Review, 94(3), 526-556.

Guiso, L., Sapienza, P., \& Zingales, L. (2006). Does culture affect economic outcomes?. Journal of Economic Perspectives, 20(2), 23-48.

Guiso, L., Sapienza, P., \& Zingales, L. (2008). Trusting the stock market. Journal of Finance, 63(6), 2257-2600.

Guiso, L., Sapienza, P., \& Zingales, L. (2009). Cultural biases in economic exchange? The Quarterly Review of Economics, 124(3), 1095-1131.

Hadenius, A., \& Teorell, J. (2007). Pathways from authoritarianism. Journal of Democracy, 18(1), 143-157.

Hall, R. E., \& Jones, C. I. (1999). Why do some countries produce so much more output per worker than others? The Quarterly Journal of Economics, 111(1), 83-116.

Harris, I. C., \& Jones, P. D. (2017). CRU CY4.01: Climatic Research Unit (CRU) year-by-year variation of selected climate variables by country (CY) version 4.01 (Jan. 1901-Dec. 2016). Centre for Environmental Data Analysis. https://doi.org/10.5285/d4e823f0172947c5ae6e6b265656c273.

Horvath, R. (2013). Does trust promote growth? Journal of Comparative Economics, 41(3), 777-788.

Inglehart, R. (1971). The silent revolution in Europe: Intergenerational change in post-industrial societies. American Political Science Review, 65(4), 991-1017.

Inglehart, R. (1977). The silent revolution: Changing values and political styles among western publics. Princeton, NJ: Princeton University Press.

Inglehart, R. (1988). The renaissance of political culture. The American Political Science Review, 82(4), 1203-1230.

Inglehart, R. (1997). Modernisation and post modernisation: Cultural, economic and political change. Princeton: Princeton University Press.

Inglehart, R. (2008). Changing values among Western publics from 1970 to 2006. West European Politics, 31(1-2), 130-146.

Inglehart, R., \& Welzel, C. (2005). Modernization, cultural change and democracy. New York and Cambridge: Cambridge University Press.

Jones, C. I., \& Romer, P. M. (2010). The new Kaldor facts: Ideas, institutions, population, and human capital. American Economic Journal: Macroeconomics, 2(1), 224-245.

Jordaan, J. A., Dima, B., \& Goleţ, I. (2016). Do societal values influence financial development? New evidence on the effects of post materialism and institutions on stock markets. Journal of Economic Behaviour and Organization, 132, 197-216.

Kashima, E. S., \& Kashima, Y. (1998). Culture and language: The case of cultural dimensions and personal pronoun use. Journal of Cross-Cultural Psychology, 29(3), 461-486.

Kaufman, D., Kraay, A., \& Mastruzzi, M. (2010). The worldwide governance indicators: Methodology and analytical issues. World Bank policy research working paper series, Paper No. 5430, available at SSRN: https://ssrn.com/abstract=1682130.

Knack, S., \& Keefer, P. (1997). Does social capital have an economic pay-off? A cross-country investigation. The Quarterly Journal of Economics, 112(4), 1251-1288.

Kravtovsa, M., Oshchepkov, A., \& Welzel, C. (2017). Values and corruption: Do postmaterialists justify bribery? Journal of Cross-Cultural Psychology, 48(2), 225-242.

Levine, R. (2005). Finance and growth: Theory and evidence. In P. Aghion \& S. N. Durlauf (Eds.), Chapter 12 in Handbook of economic growth (Vol. 1, pp. 865-934). Amsterdam: North-Holland.

Licht, A., Goldschmidt, C., \& Schwarz, S. H. (2007). Culture rules: The foundations of the rule of law and other forms of governance. Journal of Comparative Economics, 35, 659-688. 
Lloyd, P., \& Lee, C. (2016). A review of the recent literature on the institutional economics analysis of the long run performance of nations. Journal of Economic Surveys. https://doi.org/10.1111/ joes. 12186.

Maoz, Z., \& Henderson, E. A. (2013). The world religion dataset, 1945-2010: Logic, estimates, and trends. International Interactions, 39(3), 265-291.

Mullings, R. (2017). Do institutions moderate globalisation's effect on growth? Journal of Institutional Economics, 14(1), 71-102.

North, D. (1990). Institutions, institutional change and economic performance. Cambridge: Cambridge University Press.

Nugent, J. B., \& Sanchez, N. (1999). The local variability of rainfall and tribal institution: The case of Sudan. Journal of Economic Behaviour and Organisation, 39, 263-291.

Opp, K.-D. (1990). Postmaterialism, collective action, and political protest. American Journal of Political Science, 34(1), 212-235.

Ortega, F., \& Peri, G. (2014). Openness and income: The roles of trade and migration. Journal of International Economics, 92(2), 231-251.

Pagan, A. (1984). Econometric issues in the analysis of regressions with generated regressors. International Economic Review, 25, 221-247.

Peiró-Palomino, J. (2016). Social capital and economic growth in Europe: Nonlinear trends and heterogeneous regional effects. Oxford Bulletin of Economics and Statistics, 78(5), 717-751.

Pitlik, H., \& Rode, M. (2017). Individualistic values, institutional trust, and interventionist attitudes. Journal of Institutional Economics, 13(3), 575-598.

Pritchett, L. (2016). Institutions, growth accelerations and growth collapses. Economic development and institutions working paper series, no. WP16/05, Harvard University and Centre for Global Development.

Proto, E., \& Oswald, A. J. (2016). National happiness and genetic distance: A cautious exploration. The Economic Journal, 127, 2127-2152.

Rodrik, D., Subramanian, A., \& Trebbi, F. (2004). Institutions rule: The primacy of institutions over geography and integration in economic development. Journal of Economic Growth, 9, 131-165.

Sapir, E. (1970). Language. In D. G. Mandelbaum (Ed.), Culture, language and personality: Selected essays (pp. 1-44). Berkeley: University of California Press.

Spolaore, E., \& Wacziarg, R. (2009). The diffusion of development. The Quarterly Journal of Economics, 124(2), 469-529.

Spolaore, E., \& Wacziarg, R. (2013). How deep are the roots of economic development? Journal of Economic Literature, 51(2), 325-369.

Tabellini, G. (2008). Presidential address institutions and culture. Journal of the European Economic Association, 6(2-3), 255-294.

Tabellini, G. (2010). Culture and institutions: Economic development in the regions of Europe. Journal of the European Economic Association, 8(4), 677-716.

Temple, J., \& Johnson, P. A. (1998). Social capability and economic growth. The Quarterly Journal of Economics, 113(3), 965-990.

Teorell, J., Dahlberg, S., Holmberg, S., Rothstein, B., Pacho, N. A., \& Svensson, R. (2018). The quality of government standard dataset, version Jan18. University of Gothenburg: The Quality of Government Institute. http://www.qog.pol.gu.se https://doi.org/10.18157/qogstdjan18.

Welzel, C. (2010). How selfish are self-expression values? A civicness test. Journal of Cross-Cultural Psychology, 41(2), 152-174.

Welzel, C., \& Inglehart, R. (2005). Liberalism, postmaterialism, and the growth of freedom. International Review of Sociology, 15(1), 81-108.

Welzel, C., Inglehart, R., \& Klingemann, H.-D. (2003). The theory of human development: A cross-cultural analysis. European Journal of Political Research, 42, 341-379.

Westlund, H., \& Adam, F. (2010). Social capital and economic performance: A meta-analysis of 65 studies. European Planning Studies, 18(6), 893-919.

Whorf, B. L. (1956). Language, thought and reality. Cambridge: MIT Press.

Williamson, C. R., \& Mathers, R. L. (2011). Economic freedom, culture and growth. Public Choice, 148, 313-335.

Williamson, O. E. (2000). The new institutional economics: Taking stock, looking ahead. Journal of Economic Literature, 38(3), 595-613.

Wilson, M. S. (2005). A social-value analysis of post materialism. The Journal of Social Psychology, 145(2), 209-224.

Wright, J. (2008). Do authoritarian institutions constrain? How legislatures affect economic growth and investment. American Journal of Political Science, 52(2), 322-343. 
Zak, P. J., \& Knack, S. (2001). Trust and growth. The Economic Journal, 111, 295-321.

Publisher's Note Springer Nature remains neutral with regard to jurisdictional claims in published maps and institutional affiliations. 